\title{
Los procesos de profesionalización en la policía de la provincia de Buenos Aires en épocas de cambio [fines del siglo XIX y principios del siglo XX]
}

Resumen: El artículo examina las múltiples formas desplegadas por el cuerpo policial de la provincia de Buenos Aires con el propósito de profesionalizar a sus agentes en el cambio del siglo XIX al XX; periodo y espacio que han sido poco atendidos por la historiografía. Se aborda el perfil de los hombres que se insertaron en la policía - principalmente en las funciones de seguridad - y los diferentes mecanismos de reclutamiento. Asimismo, se estudian distintas instancias de capacitación y aprendizaje, como la recepción de modelos extranjeros de organización, que tuvieron un impacto significativo en la construcción de la policía como una institución moderna.

Palabras clave: policía, profesionalización, modelos internacionales, provincia de Buenos Aires.

\section{Processes of professionalization in the police of Buenos Aires province in times of change [late 19th and early 20th century]}

Abstract: The article examines the multiple forms deployed by the police force of the Buenos Aires province in order to professionalize its agents during the transition from the 19th to the 20th century, a period and geography scarcely attended by historiography. The article addresses the profile of the men who entered the police force and the different recruitment mechanisms. Different aspects of learning and training are taken into account, such as the reception of foreign organizational models that had a significant impact on the construction of the police as a modern institution. Keywords: police, professionalization, international models, Buenos Aires province.

\section{Os processos de profissionalização na polícia da província de Buenos Aires em tempos de mudança [finais do século XIX e início do século XX]}

Resumo: 0 artigo examina as múltiplas formas empregadas pela força policial da província de Buenos Aires com 0 objetivo de profissionalizar seus agentes na passagem do século XIX para o século XX, período e espaço pouco frequentados pela historiografía. São abordados o perfil dos homens que ingressaram na polícia - principalmente nas funções de segurança - e os diferentes mecanismos de recrutamento. Adicionalmente, estudam-se diferentes instâncias de treinamento e aprendizagem, como a recepção de modelos de organização estrangeiros que tiveram um impacto significativo na construção da polícia como uma instituição moderna.

Palavras-chave: polícia, profissionalização, modelos internacionais, província de Buenos Aires.

Cómo citar este artículo: Pedro Berardi, "Los procesos de profesionalización en la policía de la provincia de Buenos Aires en épocas de cambio [fines del siglo XIX y principios del siglo XX]”, Trashumante. Revista Americana de Historia Socia/ 17 [2021]: 104-124.

DOI: 10.17533/udea.trahs.n17a05

\footnotetext{
Fecha de recepción: 13 de marzo de 2020

Fecha de aprobación: 17 de julio de 2020
}

Pedro Berardi: Profesor del Departamento de Humanidades de la Universidad de San Andrés y del Departamento de Estudios Históricos y Sociales de la Universidad Torcuato Di Tella, Argentina. ORCID: 0000-0002-9387-3067

- Correo electrónico: pedroaberardi@hotmail.com 


\section{Los procesos de profesionalización en la policía de la provincia de Buenos Aires en épocas de cambio [fines del siglo XIX y principios del siglo XX]}

Pedro Berardi

\section{Introducción}

ฯ ¿Cuál es la buena policía?”, se preguntaba el ministro de Gobierno de la provincia de Buenos Aires al presentar los datos de la repartición en el ejercicio de su memoria anual. ${ }^{1}$ Sobre este interrogante las condiciones de ubicuidad, permanencia, instrucción y disciplina eran los atributos esperados en los posibles enrolados. Cómo lograrlos constituiría una preocupación neurálgica de jefes y comisarios, compartida, además, por las autoridades a cargo de la administración externa de la fuerza. ${ }^{2}$ Así, este trabajo se interesa en las múltiples formas desplegadas por el cuerpo policial de la provincia de Buenos Aires que pretendían profesionalizar

1. Ministerio de Gobierno, Memoria presentada á la Honorable Legislatura de la Provincia de Buenos Aires por el Ministro de Gobierno Ing. Francisco Seguí 1887-1888 (La Plata: Imprenta Buenos Aires, 1888) 137-138.

2. En diciembre de 1880 el ejecutivo bonaerense institucionalizó el cuerpo de policía que resultó de la escisión del existente en la ciudad de Buenos Aires. Ello se enmarcó en el proceso de redefinición del tejido político-administrativo que tuvo lugar tras la derrota de las fuerzas provinciales por parte del ejército nacional a mediados de dicho año. Ante la pérdida del centro político, las flamantes autoridades asumieron la tarea de construir un nuevo andamiaje en el que la conformación de la policía adquirió un papel fundamental. Sobre diversas experiencias previas se debatió extensamente en la Legislatura en torno al diseño del emplazamiento territorial que debían asumir las diferentes secciones que integrarían el organigrama policial. Acorde al modelo de la prefectura francesa de la Tercera República, se estableció un diseño institucional de carácter centralizado y piramidal que posibilitase un amplísimo alcance territorial, pero que al mismo tiempo estableciese la subordinación vertical a un centro único de gobierno. La elección de este esquema, en desmedro de otras propuestas que sostenían la descentralización, estuvo permeada en gran medida por la necesidad de delimitar las atribuciones que en materia policial y administrativa tenían la justicia de paz y las municipalidades. Es por esto que su administración y control fue estipulada al Ministerio de Gobierno provincial. Al respecto de las múltiples voces y perspectivas sobre las reformas institucionales, véase Pedro Berardi, “"Crear la Policía' y construir el territorio. Las reformas policiales en un nuevo orden provincial: Buenos Aires, 1878-1880", Revista de Historia del Derecho 58 (2019): 14-25. 
a sus integrantes — fundamentalmente al personal subalterno- - En pos de ello, se atiende a cambiantes criterios como a un vasto repertorio de requisitos, estrategias y prácticas que convergen y definen los procesos de profesionalización que singularizan a las policías modernas. ${ }^{3} \mathrm{Si}$ bien en el marco de este proceso la policía de la provincia de Buenos Aires en su conformación como institución moderna transitó una acelerada y acentuada especialización y ampliación de sus funciones —entre ellas burocráticas y técnicas, ${ }^{4}$ sobre todo con la creación de la Oficina de Estadística e Identificación Antropométrica-, ${ }^{5}$ las preocupaciones por disciplinar tanto para capacitar como sostener a los hombres que se enrolaban en sus filas estuvieron dirigidas sobre todo en el servicio de seguridad.

Aunque estas dimensiones han sido abordadas en investigaciones sobre la ciudad de Buenos Aires y otros espacios, hasta ahora no fueron examinadas en for-

3. Entendemos la profesionalización de acuerdo con la categorización efectuada por David Bayley a partir de su examen sobre diversas experiencias de organización policial, construida en diferentes escenarios globales desde mediados del siglo XVIII. En su observación destaca un conjunto nodal de indicadores que exceden, a su vez, criterios de especialización tales como el reclutamiento estipulado por estándares específicos, entrenamiento y capacitación formales, remuneraciones altas que posibiliten la permanencia y el avance estructurado a lo largo del desempeño de la actividad, junto a una supervisión sistemática por parte del personal de mayor rango. David H. Bayley, Modelos de actividad policial. Un análisis comparativo internacional (Buenos Aires: Prometeo Libros, 2010) 67.

4. Dentro del complejo entramado del cuerpo policial se definieron, ya desde sus momentos iniciales, una multiplicidad de reparticiones que se fueron concentrando en las dependencias de la Jefatura. Supeditadas a las actividades administrativas, prevención urbana, aprovisionamiento y a la producción y clasificación de información. La Comisaría de Órdenes — que en 1903 sería reemplazada por la Inspección General - continuaba en jerarquía al jefe de policía y tenía potestad sobre el resto de los destacamentos, mientras que la oficialidad mayor estaba a cargo de la tesorería y contaduría como del archivo y la oficina de Estadística que en 1895, junto a la Comisaría de Pesquisas, se nuclearían en la Oficina de Estadística e Identificación Antropométrica bajo la dirección deVucetich. Asimismo, se integraban otras dependencias como el cuerpo de bomberos y guardiacárceles, la alcaldía — para las detenciones temporarias—, los talleres gráficos, la banda de música y las cabellerizas. Mayormente, las funciones de seguridad quedaron supeditadas a las comisarías de sección —ordenamiento jurisdiccional de la ciudad cabecera de la provincia - y a las comisarías de partido en el resto del escenario bonaerense. Ambas bajo la supervisión del cuerpo de inspectores con asiento en la Jefatura hasta 1903. Mientras que las comisarías de Tablada condensaron atribuciones de "baja policía", operaban en los circuitos de comercialización de ganado. Para el cambio de siglo y acorde a las crecientes exigencias del territorio, tales funciones se complementaron y ampliaron con la creación de cuerpos especializados, abocados en gran medida a la represión del cuatrerismo y a la creciente conflictividad social. Este artículo se focaliza en los agentes policiales que suplían funciones de seguridad, un cuadro mayor acerca del personal técnico y burocrático puede consultarse en Pedro Berardi, "Territorialidad, profesionalización y política. La construcción de la policía en la provincia de Buenos Aires, 1880-1916" (Tesis de doctorado en Historia, Universidad de San Andrés, 2018) 212-214.

5. Mercedes García Ferrari, Marcas de identidad. Juan Vucetich y el surgimiento transnacional de la dactiloscopia (1888-1913) (Rosario: Prohistoria Ediciones, 2015). 
ma conjunta para el contexto aquí considerado. ${ }^{6}$ En igual sentido, proponemos rescatar las especificidades de un periodo que ha sido escasamente transitado por los estudios policiales más recientes, en el marco de la revisión de los escenarios provinciales, como lo es el del cambio de siglo hasta los primeros años de la década de 1910. Así, resulta de interés recomponer una agenda de intereses particulares de los actores policiales que, si bien tuvo una gran correspondencia con los designios de distintos grupos políticos, posibilitó una visión particular acerca de las órdenes que se les impartían, así como definió actividades, problemas e ideas propios del derrotero de la institución.

En este marco, en primer lugar, daremos cuenta tanto del perfil de los hombres que la integraban como de los principales mecanismos y motivaciones de inserción y reclutamiento. Asimismo, consideraremos las estrategias desplegadas por la cúpula para efectivizar la conformación de planteles estables y disciplinados. Atendemos, fundamentalmente, al impacto del salario, junto a otras modalidades de enganche de carácter interrelacional, en la dinamización de los reclutamientos. Sobre esta experiencia, repondremos los principales rasgos de un conjunto de modelos, discursos, prácticas y textos que con una lógica programática y rutinaria o con un tono pedagógico orientaron la profesionalización. El análisis de estos sucesivos marcos generales de referencia es puesto en relación con el devenir de la propia experiencia del quehacer policial del periodo. Considerando este sustrato, abordaremos por último un conjunto de modelos, prácticas y publicaciones policiales que también fueron afines a la concreción de un proceso complejo signado por avances y retrocesos, así como tanto por la adopción de las innovaciones organizacionales como por la apelación a mecanismos de instrucción o aprendizaje configurados desde la propia experiencia.

\section{1. "Bárbaros inestables y civilizados desprotegidos": caracterización de los policías}

De acuerdo con la propuesta de David Bayley, quienes conforman la policía no suelen pertenecer a las clases altas y cultas. En buena medida porque la actividad requiere elevados niveles de exposición física y se realiza en ámbitos estrechamente conectados a paisajes sociales conflictivos. ${ }^{7}$ Dichas razones la vuelven menos atractiva que otros trabajos. Ello se refleja, además, en distintas situaciones como la recurrencia a las bajas, los desplazamientos y las solicitudes de ingreso que han sido examinadas para las policías de la ciudad de Buenos Aires y de otros escenarios provinciales y latinoamericanos. ${ }^{8}$ Estas características pueden identificarse también

6. Destacamos al respecto los estudios de Osvaldo Barreneche, que resultan cardinales en su reconstrucción sobre la institución policial bonaerense desde 1880 hasta los tempranos años setenta. Osvaldo Barreneche, De brava a dura. Policía de la Provincia de Buenos Aires. Una historia (1930-1973) (Rosario: Prohistoria Ediciones, 2019).

7. Bayley 19.

8. Como el mapa bibliográfico es vasto, nos permitimos referir a los siguientes trabajos. Para el espacio 
en el contexto abordado. Al menos hasta el cambio de siglo, tanto en la literatura popular como en las crónicas dedicadas a la policía y en las producidas por esta, las imágenes se repiten. Así se suceden “el compadrito” o "el policiano”. Motes que, aunque peyorativos por exaltar atributos asociados a la brutalidad, no resultaban, sin embargo, lejanos del perfil social de los subalternos. Quienes elegían vestirse de uniforme provenían en efecto mayoritariamente de los sectores sociales más bajos, con una capacitación insuficiente para aspirar a otras labores que requiriesen de mayor especialización.

De acuerdo a los mecanismos pautados por el reglamento general de $1881,{ }^{9}$ el Poder Ejecutivo se reservaba la designación de oficiales y administrativos, pero los comisarios a cargo en la selección del personal de facción debían disponer mayoritariamente de aquellos que "se presentan solicitando sentar plaza, con una carta de recomendación cualquiera". ${ }^{10}$ A su vez, las posibilidades de proyectar una carrera dentro del escalafón solo permitían alcanzar el grado de sargento. ${ }^{11}$ Para fines del siglo XIX dada la laxitud de los controles, la ausencia de exámenes de admisión, la imposibilidad de acceder a los escaños superiores del escalafón y las constantes demandas para completar vacantes, la plaza de policía solía provocar numerosos desplazamientos y bajas. $^{12}$

local véase, entre otros, Viviana Barry, "Policía y reclutamiento. Hombres y organización policial en Buenos Aires, 1880-1910" (Ponencia, XII Jornadas Interescuelas / Departamentos de Historia en San Carlos de Bariloche, 2009); Gabriel Carrizo, "'Pobres peligrosos e incapaces'. La policía del Territorio Nacional del Chubut entre fines del siglo XIX y primeras décadas del siglo XX", Historia social y política del delito en la Patagonia, comp. Gabriel Rafart (Neuquén: Editorial de la Universidad Nacional del Comahue, 2010) 295-310; Melisa Fernández Marrón, “El agente policial / modelo para armar. Estrategias institucionales de profesionalización en el territorio nacional de La Pampa (1930-1950)" (Ponencia, I Jornadas Nacionales de Historia Social, 2007). Sobre Brasil referimos a Marcos Luiz Bretas, A guerra das ruas. Povo e polícia na cidade do Rio de Janeiro (Río de Janeiro: Arquivo Nacional, 1997). Para el caso de Chile, Vania Cárdenas Muñoz, El orden gañán. Historia social de la policía. Valparaíso, 1896-1920 (Chile: Ediciones Escaparate, 2013); para el de México, Diego Pulido Esteva, “Trabajo, clase y prácticas policiales en las comisarías de la ciudad de México, 1870-1920”, Historia Mexicana 68.2 (2018): 667-712. DOI: 10.24201/hm.v68i2.3749.

9. Registro Oficial de la Provincia de Buenos Aires (Buenos Aires: Imprenta de la Penitenciaría, 1880) 794.

10. Provincia de Buenos Aires, Memoria del Departamento de Policía, presentada por Juan A. Domínguez, 1887-1888 (La Plata: Imprenta Buenos Aires, 1889) 18-19.

11. El sistema de ascensos consolidado hacia fines de 1880 preveía la movilidad en el grado desde los vigilantes hasta los sargentos de segunda categoría. Formalmente, los comisarios u oficiales a cargo de la dotación proponían a la Jefatura una nómina de agentes que reuniesen las siguientes condiciones: tener entre 22 a 45 años, acreditar buena conducta, antigüedad, competencia o haber realizado alguna acción meritoria digna del reconocimiento institucional. Asimismo, se consideraban las solicitudes de bajas y los ocasionales reingresos al puesto. Reglamento General de Policía de la Provincia de Buenos Aires (La Plata:Tipografia Buenos Aires, 1889) 59.

12. Para 1887 , único año del que disponemos información sobre la tropa, el total de 2,636 individuos produjeron 3,731 movimientos. Alarmado, el Ministro de Gobierno desagregaba el resultado de esta dinámica:"se acordaron, por solicitud voluntaria de los mismos agentes, 2372 bajas. Tal dato, que puede decirse se refiere á los que tienen aptitudes, encuentra su reverso en otro que significa la lucha para eliminar á los que no las tienen, y que lo representa la suma de 1359 individuos 
Así, para muchos hombres la policía implicó el acceso, fuera o no temporario, si deseaban permanecer en sus cargos, a recursos como el jornal, una vivienda o la vestimenta. Podían sustituir o complementar una situación de precariedad laboral a cambio de la estabilidad en una repartición pública, incluso, si se tenía en cuenta la exigüidad de los salarios, sobre la que nos detendremos más adelante. De igual manera, constituía un ámbito al que podían ingresar personas que hubieran cometido algún acto delictivo. La insuficiencia en los registros, principalmente en las zonas rurales, impedía en efecto disponer de datos sobre los antecedentes, lo cual facilitaba a los agentes obtener rápidamente el alta en caso de haber sido expulsados de otras jurisdicciones.

Con todo, solicitar el puesto de vigilante permitía también el empleo para quienes culminaban una amplia trayectoria miliciana, iniciada en las guardias nacionales y en el ejército de línea. En igual sentido, la experiencia en el servicio policial fronterizo era también altamente considerada al momento de la selección en el puesto. Fundamentalmente, porque la instrucción y la disciplina castrense fueron contempladas por la cúpula como una de las opciones más adecuadas para formar a la tropa y diseñar algunos cuerpos especializados. Es por lo que mediante esas incorporaciones se pretendía lograr que los agentes moldeados en la vida militar transmitieran a sus pares un abanico de conocimientos y comportamientos que se traducirían en el métier policial. Sobre este sustrato no era excluyente la inserción para aquellos que provenían de los “bajos fondos”, como lo era para migrantes provincianos y ultramarinos. El último conjunto, además de disponer de un empleo, encontraba la oportunidad de insertarse dentro del tejido social, principalmente, si carecían de otras redes de parentesco o paisanazgo que los contuviesen. Sin embargo, esto parece no haber sido un fenómeno tan extendido, como fue señalado para la policía metropolitana durante los mismos años. ${ }^{13}$

En definitiva, los planteles fueron mayoritariamente engrosados por criollos con arraigo en el espacio bonaerense. Se trataba de jornaleros, labradores o trabajadores estacionales que posiblemente no lograron articularse en forma exitosa al proceso de transformación socioeconómica, que por entonces encontraba en la inmigración masiva y en la reconfiguración productiva sus principales puntales. ${ }^{14}$

dados de baja por falta de cumplimiento á su deber, abusos y delitos de diversa índole, muchos de los cuales obligaron á entregar los causantes á la justicia, por la calidad de sus faltas". Provincia de Buenos Aires 18.

13. Los trabajos de Sandra Gayol han sido los primeros en abordarlos. Sandra Gayol, "Sargentos, cabos y vigilantes: perfil de un plantel inestable en el Buenos Aires de la segunda mitad del siglo XIX", Boletín Americanista 46 (1996): 133-151; Sandra Gayol, "Entre lo deseable y lo posible. Perfil de la policía de Buenos Aires en la segunda mitad del siglo XIX", Estudios Sociales 10 (1996): 123-138. DOI: 10.14409/es.v10i1.2355. En igual sentido referimos a Diego Galeano,"O oficio inconfessável: policiais, ordem urbana e mercado de trabalho na cidade de Buenos Aires, 1867-1880", Revista do Arquivo Geral da Cidade do Rio de Janeiro 9 (2015): 191-209.

14. Para una descripción de las transformaciones socioeconómicas de la provincia véase Leandro Losada, "La sociedad bonaerense: tendencias demográficas, grupos sociales y formas de vida", Historia de la Provincia de Buenos Aires. De la federalización de Buenos Aires al advenimiento del peronismo 
Combinado a ello, en las comisarías emplazadas en la frontera suroeste el reclutamiento alcanzaba también a indígenas, como sucedía en los cuerpos de las policías territorianas. ${ }^{15}$ En lo respectivo a los escaños superiores, en cambio, puede observarse una situación muy diferente, ya que la mayoría pertenecía a sectores sociales más acomodados. Asimismo, a la par que su designación obedeció principalmente a una trayectoria previa en distintas ramas del estado, la legitimidad y las redes que podían configurarse desde el tejido policial fueron fundamentales para efectivizar la participación en cargos políticos. ${ }^{16}$

Como anticipamos, para las cúpulas fue cardinal dar solución a la transitoriedad y falta de instrucción de la tropa. A tal fin, una de las cuestiones salientes fue el reclamo por el incremento de los jornales por considerarlo uno de los indicadores más importantes en la profesionalización de la fuerza. Un breve balance de su evolución en el periodo nos brinda otros elementos de interés para el análisis.

\section{La dimensión salarial y las estrategias de ingreso a la fuerza}

Tanto las condiciones económicas como las frecuentes confrontaciones políticas se conjugaron para que el nivel de los salarios no supliese las expectativas policiales, así como impactó decisivamente en la dinámica del servicio. ${ }^{17}$ Atendiendo a su evolución, observamos que entre 1881 y 1886 se advierte una tendencia a la baja, con excepción de los sargentos que cumplían funciones en las comisarías emplazadas en la capital provincial (La Plata). Sin embargo, dicha tendencia comenzó a revertirse entre 1886 y 1891, años en los que la expansión de la economía bonaerense estuvo acompañada por la estabilidad institucional, en tanto los

(1880-1943), t. 4, dir. Juan Manuel Palacio (Buenos Aires: UNIPE Editorial Universitaria / Edhasa, 2013) 130-141.

15. Pilar Pérez, "De la ocupación militar del Desierto a la práctica policial como productoras del espacio social en Nor-Patagonia (Río Negro, 1884-1914)" (Ponencia, Jornada de Debate: "Administración territorial, milicia y policía en perspectiva comparada: Buenos Aires y Río Negro entre 1852 y 1916", 2017).

16. Algunos itinerarios de jefes, inspectores u oficiales indican que su transcurso por la repartición podía ser capitalizado para afianzar las proyecciones en otras actividades públicas. Así lo ejemplifican los jefes - de quienes consignamos las fechas en las que ocuparon el cargoJulio S. Dantas (1880-1886 y 1893, de manera interina), Carlos Costa (1880-1890), Luis María Doyhenard (1902-1906 y 1914-1916), Juan B. Lavié (1908-1910) y Juan Taquini (1910-1912), quienes al culminar sus gestiones se desempeñaron como legisladores provinciales o nacionales del Partidos Autonomista Nacional y, a partir del siglo XX, del Partido Conservador. Asimismo, Doyhenard — quien falleció ejerciendo su cargo de máxima autoridad en la institución, en abril de 1916 - había sido candidato a gobernador bonaerense en 1906 y cuatro años después designado como comisionado en la ciudad de La Plata, para ser reelegido en la Jefatura. Berardi, “Territorialidad, profesionalización y política" 149.

17. Esta dimensión fue exhaustivamente analizada en Gisela Sedeillan y Pedro Berardi, "El desafio de la policía bonaerense en la década de 1890: entre la expansión institucional y el estancamiento de sus recursos", Prohistoria 18.23 (2015): 71-96. 
recambios en la gestión gubernamental solo tuvieron lugar en la competencia al interior de las filas oficialistas.

En este marco, la preeminencia salarial de la capital se mantuvo no solo para los sargentos, sino también para los cabos y vigilantes que vieron incrementados sus estipendios, aunque en una proporción inferior de acuerdo con su rango. Por ejemplo, en 1891 un sargento que cumplía el servicio en La Plata cobraba \$117 m.n. mensuales, mientras uno de la campaña recibía $\$ 45$ m.n.; al tiempo que un vigilante de la capital percibía $\$ 50$ m.n. a diferencia de uno de campaña con $\$ 40$ m.n. ${ }^{18}$ Aunque con menor desplazamiento, pero sí en una situación de exposición para nada desdeñable, los salarios mensuales del personal subalterno del servicio de guardiacárceles eran inferiores a los correspondientes del personal de comisarías. ${ }^{19}$ Claro que, debido a la multiplicidad de funciones que debían cumplirse como a la extensión del territorio en el que se operaba — sobre todo en las zonas rurales-, esta remuneración era percibida por los policías como insuficiente. Ante el peso que suponían las tareas, resultaba más atractivo combinar el servicio con actividades más remunerativas como las rurales en los periodos de cosecha, con las cuales se provocaba un constante movimiento de bajas y reingresos. En igual sentido, debe considerarse que muchos percibían a la ciudad de Buenos Aires como un mejor escenario laboral, sea porque allí las remuneraciones eran más altas o por su menor rango territorial, que aligeraba las tareas. ${ }^{20}$

Sin embargo, en el transcurso de la siguiente década los efectos de la crisis económica, aunados a la confrontación cada vez más abierta entre los grupos disidentes con fuerte gravitación en la legislatura y el poder ejecutivo, afectaron notablemente la gestión de las partidas presupuestarias destinadas a la repartición. Debido a las crecientes impugnaciones hacia las gestiones vinculadas al Partido Autonomista Nacional propiciadas por los levantamientos de la Unión Cívica y el radicalismo durante 1893, la policía se tornó en el epicentro de las críticas con base en sus posibles realineamientos con los gobernadores y con las autoridades comunales. Esta situación se agravaría, no obstante, a partir de la asunción del mandatario radical Bernardo de Irigoyen en 1898.

Toda su administración estuvo atravesada por una férrea oposición parlamentaria que se tradujo en el estancamiento del presupuesto provincial. Distintas áreas de la esfera pública experimentaron un notable descenso en la asignación de los

18. Este análisis se apoya en la revisión de los presupuestos generales de gastos y recursos aprobados por la legislatura provincial publicados en los diarios de sesiones de la Cámara de Diputados y Senadores de la provincia de Buenos Aires. Para los años: 1881, Ley 1378; 1886, Ley 1803; 1891 , Ley 2395; 1896, Ley 2563; 1901, Ley 2745; 1906, Ley 2972; 1911, Ley 3317; 1916, Ley 3612. http://www.gob.gba.gov.ar/dijl/buscador.php?id=01 (09/01/2018).

19. Para 1891 el salario mensual de un sargento primero del Batallón de Guardiacárceles era de $\$ 35$ m.n., mientras que el de un sargento segundo era de \$30 m.n. El ingreso de los soldados, en cambio, era de $\$ 22$ m.n. Véase 1891, Ley 2395. http://www.gob.gba.gov.ar/dijl/buscador. php?id=01 (09/01/2018).

20. Por ejemplo, en 1897 el salario mensual de un agente de la provincia no superaba los $\$ 50$ m.n., mientras que en la Capital Federal alcanzaba los $\$ 65$ m.n. Véase Sedeillan y Berardi 79. 
recursos. Con escasos avances, la policía resultó mayormente afectada debido a que los legisladores para debilitar su intervención política desestimaron las solicitudes de aumento requeridas desde el ejecutivo, hasta el extremo de embargar los jornales en los momentos más álgidos de la confrontación electoral. En términos generales esto implicó que el monto salarial se estacionase en los niveles que se habían alcanzado para 1891. Solo en 1900 el creciente malestar de las jerarquías institucionales junto a las demandas sociales ante la proliferación del abigeato en la zona rural conllevó a un ajustado incremento para los cabos y vigilantes de la capital y los partidos, que se mantendría sin modificaciones hasta seis años después.

Este cuadro, empero, comenzaría a modificarse en los años subsiguientes. Durante la etapa inaugurada por el gobernador Marcelino Ugarte, desde 1902, el ordenamiento de las finanzas provinciales acompañadas de un acuerdo electoral que le confirió legitimidad a su gestión posibilitaron que la dimensión salarial adquiriese un nuevo impulso, hasta alcanzar en 1911 su escala más alta durante el periodo. No obstante, en los siguientes años los mismos tendieron nuevamente a la baja, si bien se mantuvieron en un piso superior al de comienzos de siglo. Esto se explica en que la estabilidad económica provincial se vio amenazada por el impacto de la crisis de $1913 .^{21}$

A estas fluctuaciones sobre los salarios debe añadirse que los mecanismos por los cuales se consumaba la remuneración de la tropa dificultaban su apercibimiento inmediato. El sistema de pago preveía que el oficial $1^{\circ}$ tenía que convocar al personal a la oficina central los primeros días del mes, del mismo modo en que durante esa jornada debía desplazarse hacia los partidos más próximos para garantizar el cobro. En las localidades más distantes, en cambio, se realizaba el depósito en las sucursales del Banco de la Provincia. No obstante, debido a la insuficiencia de estas dependencias resultó más usual que el jefe acordara con los comerciantes el anticipo del estipendio a los empleados, cuyo servicio había sido previamente verificado por el juez de paz. Esos adelantos debían ser posteriormente corroborados por los funcionarios municipales y por el Departamento Central. ${ }^{22}$

Más allá de satisfacer el propósito de celeridad y control proyectado por las autoridades bonaerenses, la lógica de este sistema fue consolidando una red de subvenciones y préstamos que distaba de la prescindencia de los poderes comunales. Al respecto, desde la prensa y las bancas legislativas como también en las más altas esferas del cuerpo policial eran recurrentes las denuncias que tomaban a caudillos e intendentes junto a comisarios como miembros de una trama cimentada en el intercambio de favores, ya que aquellos podían dinamizar, incrementar o reducir los pagos apelando a sus influencias. En igual sentido, estos engranajes favorecían

21. Fernando Rocchi, "La economía bonaerense: del auge exportador a su crisis", Historia de la Provincia de Buenos Aires. De la federalización de Buenos Aires al advenimiento del peronismo (18801943), t. 4, dir. Juan Manuel Palacio (Buenos Aires: UNIPE Editorial Universitaria / Edhasa, 2013) 115.

22. Carlos D’Amico, Siete años en el gobierno de la provincia de Buenos Aires (Buenos Aires: Imprenta, Litografia y Encuadernación de Jacobo Peuser, 1895) 108-109. 
prácticas informales que posicionaban a comerciantes e incluso a oficiales de mayor rango como prestamistas de los subalternos. Tales vínculos se intensificaban en aquellos contextos, como el de comienzos de siglo, donde la distribución del presupuesto quedaba plenamente estancada.

Por otra parte, las relaciones interpersonales tenían también un peso decisivo al momento de obtener un cargo dentro de la repartición. Del mismo modo en que lo ha demostrado Marcos Luiz Bretas para la conformación de la tropa imperial brasileña, resultaba frecuente que los aspirantes o algún familiar se sirviesen de sus contactos con autoridades políticas o policiales para peticionar una vacante. ${ }^{23}$ Esta estrategia, asimismo, era empleada por quienes ya habían cumplido con el servicio y peticionaban su reincorporación, solicitaban la promoción o anhelaban el traspaso de su cargo al momento de efectuarse los reemplazos políticos o las bajas al interior del escalafón.

El costo de vida allí donde se cumplían las funciones, la lejanía de la familia, alguna enfermedad o las aspiraciones de ascenso, entre otras circunstancias o motivaciones, constituían razones de peso para concitar los favores de una extensa red de mediadores. Las posibilidades de éxito estaban determinadas por la intensidad de las relaciones con quienes ocupaban la Jefatura. Aunque, de acuerdo con las lógicas de la actividad pública, resultaba frecuente que esas demandas se canalizaran no solo a través de los mismos superiores, sino de otros funcionarios como intendentes y comisionados, letrados, militares o jefes del Registro Civil.

Debemos destacar que esta lógica imperaba también en situaciones de nombramientos o remociones de oficiales como de auxiliares. La particularidad del caso en lo concerniente a la designación de cargos jerárquicos es que ocasionalmente los actores comunales intervenían en esa decisión. El buen desempeño de sus funciones constituía el principal capital simbólico considerado a escala local para que un comisario o un subcomisario pudiesen permanecer o ser removidos de sus puestos. ${ }^{24}$ Claro que esas atribuciones estaban también combinadas con su capacidad de intervención política. Sobre ello, cabe resaltar que en determinadas coyunturas - principalmente durante las administraciones de Luis María Doyhenard, en los periodos 1902-1906 y 1914-1916 - la movilización como la desarticulación del electorado, de igual forma que la construcción de coaliciones y la detención de opositores, constituyeron elementos de peso para asegurar la designación en puestos neurálgicos dentro del tejido policial.

Como hemos anticipado, la pervivencia de estos mecanismos de reclutamiento lejos de poner en tensión la anhelada profesionalización de la fuerza, posibilitó que fuesen integrados debido a que resultaban los más eficaces al momento de sostener

23. Marcos Luiz Bretas, "La policía de la capital del Imperio Brasilero", Mirada (de) uniforme. Historia y crítica de la razón policial, coords. Diego Galeano y Gregorio Kaminsky (Buenos Aires: Editorial Teseo, 2011) 105.

24. "1881-1884: Solicitudes y nombramientos", julio de 1881. AGN, Buenos Aires, Colecciones Particulares, Fondo Dardo Rocha, Sala 7, leg. 2879. 
la estabilidad de los planteles. ${ }^{25}$ Del mismo modo, en determinados contextos, eran dinamizados desde la Jefatura para configurar tramas de legitimidad en los escenarios locales. En este devenir, a la definición de las estrategias para ajustar la selección del personal y su permanencia se sumaron otras iniciativas. En efecto, la construcción de un cuerpo policial profesionalizado supuso un arduo proceso de experimentación y ensamblaje de múltiples modelos, experiencias e instancias académicas. Al igual que en otros casos de construcción de policías modernas, tal como observaremos a continuación, esto implicó la combinación de elementos propios de sistemas desarrollados en diversas latitudes con esquemas y saberes constituidos a partir del ejercicio cotidiano de la actividad. ${ }^{26}$

\section{La instrucción: textos y escuelas}

Avanzar en la profesionalización implicó delimitar esferas y atribuciones tanto al interior del cuerpo como entre este y el cambiante tejido social, político y territorial. A tal fin, se conjugaron distintos conjuntos normativos nucleados en la intención de "civilizar" a quienes integraban la policía como también de ordenar su actividad. En relación con ello, Osvaldo Barreneche ha examinado la manera en que las rutinas cotidianas se fueron configurando desde los primeros días de la repartición por la remisión de las órdenes del día. Desde el Departamento Central periódicamente se enviaban a todas las comisarías de sección y de campaña un conjunto que incluía disposiciones y ordenanzas, solicitudes de capturas, guías de marcas, modificaciones legislativas, lista de padrones y de mesas electorales y notificaciones de ascensos o de exoneraciones. ${ }^{27} \mathrm{~A}$ los que se añadían los edictos y las disposiciones municipales que estipulaban a nivel local las facultades contravencionales para el ordenamiento del ámbito público.

25. Por ejemplo, hemos concluido que la referida gestión de Luis Doyhenard combinó en sus dos periodos una acentuada correspondencia de los actores que integraban la fuerza con la dirigencia política de la provincia, además de un fuerte proceso de profesionalización que se tradujo en un conjunto de reformas que modificaron sustancialmente el servicio. Junto al despliegue del equipamiento técnico con la extensión de las líneas telegráficas, la intensificación de la represión al abigeo, la conformación de cuerpos especializados — de los que aquí damos cuenta—, la supresión de la Comisaría de Órdenes por la Inspección General y un régimen de inamovilidad del personal subalterno, que fue precedido por un intenso proceso de exoneraciones y recambios, Doyhenard efectivizó mejoras significativas en el servicio, con lo que vehiculizó mecanismos de inserción informal en los que predominaba sobre todo la filiación política de los agentes. Al respecto véase Pedro Berardi, "Hacerse visible, mostrarse discreto. El Fondo Luis Doyhenard como cartografia de las confluencias entre la política y la profesionalización policial (1898-1916)”, Revista Electrónica de Fuentes y Archivos 6 (2015): 140-159.

26. Este aspecto ha sido advertido por Clive Emsley, "Los modelos de policía en el siglo XIX", Mirada (de) uniforme. Historia y crítica de la razón policial, coords. Diego Galeano y Gregorio Kaminsky (Buenos Aires: Editorial Teseo, 2011) 21-47.

27. Osvaldo Barreneche, "Manejo metodológico de las fuentes documentales y los archivos de la policía de la provincia de Buenos Aires" (Ponencia, XXVIII Congreso Internacional de LASA, 2019). 
Ese conjunto normativo se integraba con otros textos, cuyo carácter era más prescriptivo. Al respecto, la confección del Reglamento General de Policía de 1881 sentó las bases organizativas de la institución, y respondió a su carácter centralizado. Redactado por su primer jefe, Julio Secundino Dantas, e inspirado en los reglamentos de la policía francesa de 1875 y 1877, ordenaba y homogeneizaba las jerarquías, funciones y atribuciones correspondientes a cada una de las secciones y su personal. De igual modo, definía los alcances de la intervención policial con respecto a otras esferas estatales, fundamentalmente con la justicia de paz. Para completar el carácter burocrático con disposiciones prácticas, se incorporó, asimismo, un manual de instrucción con arreglos al Manual de procedimientos que regía para el cuerpo de la ciudad de Buenos Aires desde 1880. Se pretendía con ello clarificar las intervenciones del personal en las instancias correccionales en las que había ido ganando mayor participación con el propósito de impedirle "la arbitraria interpretación de las ordenanzas no copiladas y no comentadas", ${ }^{28}$ y mitigar así el carácter "inquisitivo" asumido en los procesos de indagatoria.

La noción de "civilizar" a comisarios y agentes, en un contexto en el que la fuerza policial iba adquiriendo mayor protagonismo en los procedimientos penales ante las reformas propiciadas sobre la justicia lega, ${ }^{29}$ se cristalizaría con mayor énfasis en el nuevo Reglamento General de Policía. Para 1888, ante el crecimiento de la repartición, la especialización y la creación de nuevas áreas - como la Comisaría de Pesquisa - ${ }^{30}$ junto a la ampliación de funciones, el entonces gobernador Máximo Paz nombró una comisión encargada de su redacción. Tomando como referencia el reglamento vigente, se introdujeron algunas modificaciones que posibilitaban a oficiales, sargentos y cabos actuar de oficio o mediante denuncias en el esclarecimiento de homicidios, robos, atentados contra la propiedad, aborto e infanticidio $\mathrm{y}$ actos que pusieran en cuestionamiento al orden social, como levantamientos o sediciones. ${ }^{31}$ Se continuaban delineando así las esferas de intervención y la unificación de las funciones para todo el escalafón.

De igual manera, se insistiría ante las deficiencias de este sistema en la importancia de las formas de instrucción más de una década después de sancionado el reglamento. En 1904 se elaboró el "Programa para la Instrucción de Sargentos, Cabos y Vigilantes" que fue distribuido en todas las comisarías. Este constituía un compilado de "ejemplos prácticos" y preguntas breves que pudieran uniformar y agilizar el proceder de la tropa. Por su parte, el complemento con los "ejemplos prácticos" reforzaba el carácter didáctico del texto. Así, entre otras cuestiones se

28. Policía. Manual de procedimientos (Buenos Aires: Imprenta y Litografia de Buenos Aires, 1881) 6.

29. Gisela Sedeillan, La justicia penal en la provincia de Buenos Aires. Instituciones, prácticas y codificación del derecho (1877-1906) (Buenos Aires: Editorial Biblos, 2012) 65-71.

30. Aunque la creación de la Comisaría de Pesquisas fue estipulada en el proyecto de presupuesto para 1889 , no fue sino hasta el siguiente año que comenzó a funcionar como una de las secciones de la Jefatura y tomaba el modelo de la repartición porteña.

31. Reglamento General de Policía 19 y 49. A pesar de los sucesivos intentos no se realizó una nueva modificación del reglamento hasta mediados de la década de 1930. 
indicaba como inadecuada la conducta del agente que "en vez de proceder contra los contraventores se muestra tolerante y hace caso omiso de la contravención" y de las leyes municipales. ${ }^{32}$

La codificación plasmada en las órdenes del día, reglamentos y manuales de procedimiento, junto a las disposiciones de las distintas municipalidades, implicaron entonces una suerte de guía ecléctica para la definición de lo que era esperable y permisible en oficiales, administrativos y vigilantes. Este proyecto se expandiría y complejizaría con la formalización de canales de instrucción, cuyos alcances eran mucho más masivos.

Al respecto, la creación de escuelas destinadas al personal subalterno se había planificado durante la etapa inicial de la repartición. Una primera experiencia se llevó a cabo en 1887. Si bien la Jefatura consideró la obligatoriedad de asistencia a todos los aspirantes, debido a los bajos salarios la cantidad del personal ingresado en la repartición resultó insuficiente para completar los cursos. Por lo tanto, solo se estipuló la concurrencia de sargentos enviados desde todas las comisarías a la escuela instalada en el Departamento Central. La dinámica fue establecer una cadena de transferencia de los saberes allí aprendidos, que denota una visión policial orgánica y corporativa; ya que al culminar esa etapa los graduados debían transmitir a sus subordinados la enseñanza recibida. ${ }^{33}$

Recién dos décadas después este proyecto se potenciaría cuando se logró instituir escuelas para la formación y capacitación del personal raso. ${ }^{34}$ Los niveles de especialización, junto al incremento de las partidas presupuestarias, dieron lugar a la creación en las dependencias contiguas a la Jefatura de una escuela para aspirantes y otra para vigilantes en 1912. Su particularidad fue que definieron requisitos específicos de incorporación y de promoción. Así, en el caso de los vigilantes era "condición indispensable para ingresar [...] ser ciudadano natural ó legal, gozar de buena salud, no tener más de cuarenta años y medir 1.70 de talla como mínimum". ${ }^{35}$ Mientras que solo en caso de aprobación de los exámenes se los proponía, de acuerdo a sus calificaciones, para escribientes o bien para cabos o sargentos de segunda y primera categoría. ${ }^{36}$ De igual forma, se pautaba el quehacer policial en diversas fases. En el primer tiempo no se "recomendaba salir a la calle",

32. Policía de la Provincia, Programa para la instrucción de sargentos, cabos y vigilantes. Arreglado al Reglamento de Policía en vigencia (La Plata:Talleres de Policía, 1904).

33. Provincia de Buenos Aires 7.

34. Esta experiencia pedagógica, no obstante, se vería interrumpida por razones políticas en abril de 1917, tras la intervención federal a la provincia. Nueve años después se intentó formalizar otra escuela para aspirantes, aunque sus alcances serían más bien limitados. No sería hasta la década de 1940 cuando el cuerpo policial lograría establecer de manera definitiva cursos de formación y promoción para subalternos y suboficiales, como así también la incorporación de personal femenino en el marco de las transformaciones sociales impulsadas por el peronismo. Barreneche, De brava a dura 49-57.

35. Policía de la Provincia de Buenos Aires, Memoria correspondiente al año 1912. Mejoras en el servicio, jefatura del Sr. Juan Carlos Chaumeil (La Plata:Talleres de Policía, 1913) 25.

36. Policía de la Provincia de Buenos Aires 25. 
ya que se entendía que era mejor la lectura reiterada del reglamento y la explicación "concisa y clara" de sus deberes. Luego, con la finalidad de poner en práctica los conocimientos adquiridos, se les hacía prestar servicio tanto en las dependencias del Departamento como en otros destinos en los que pudieran cumplir una misión específica, como en los ámbitos de ocio veraniego.

Se esperaba que en el cumplimiento de estas rutinas como en su desempeño futuro a lo largo de todo el territorio pudieran efectivizar el amplio repertorio en el que eran instruidos. En efecto, se enfatizaba que el "buen policía" debía poseer conocimientos sobre toda la campaña de la provincia, sus centros de población, red de ferrocarriles, líneas telegráficas y su topografia. ${ }^{37}$ De igual manera, la dimensión profesional suponía, junto al estricto dominio del reglamento, la adquisición de determinadas destrezas acordes al perfil técnico que la policía asumiría en su proceso de modernización, entre otras: dactiloscopia, telegrafia, aritmética, nociones de anatomía y fisiología. La instrucción militar y la esgrima, junto a la práctica sumarial, constituían por su parte las principales materias por las que se acentuaba la relación de la policía con la justicia y la adopción de la formación militar. Finalmente, los programas contemplaban las disposiciones acordes a la intervención pública: definiciones y tipificaciones de los delitos, régimen de contravenciones, legislación nacional y provincial e instrucción cívica. ${ }^{38}$ Esto último era fundamental en un contexto en el que la policía estaba atravesada por fuertes procesos de reforma política tras los cambios en materia electoral que había introducido la sanción de la Ley “Sáenz Peña” en 1912.

\section{El esquema militar y los sistemas policiales transoceánicos}

Para el cambio de siglo, ante los efectos indeseados por los procesos de politización que habían permeado a los actores policiales en las décadas precedentes, tanto las cúpulas como algunos expertos establecieron un significativo debate respecto a la reestructuración de los modelos de acción policial. ${ }^{39} \mathrm{Si}$ bien el fortalecimiento de las áreas técnicas dentro del tejido institucional, además de los desafios que imponían las crecientes conexiones espaciales por fuera del ámbito bonaerense, ${ }^{40}$ implicaban mayores exigencias en la capacitación, la mayor parte de los esfuerzos

37. Policía de la Provincia de Buenos Aires 26.

38. Policía de la Provincia de Buenos Aires 27.

39. Los debates que se dieron a comienzos de siglo respecto a los modelos para construir a la "buena" policía involucraron exclusivamente a los propios actores institucionales. En torno a esto se consideraron algunos modelos transnacionales disponibles, principalmente del Bobby británico. No obstante, dicha referencia fue descartada inmediatamente debido a que no se ajustaba ni al perfil social de los ingresantes ni resultaba adecuada para las necesidades de la campaña. Sobre la importancia de este modelo y sus implicancias, véase Clive Emsley, "The Policeman as Worker: A Comparative Survey c. 1800-1940”, International Review of Social History 45.1 (2000): 89-110.

40. Diego Galeano, Criminosos viajantes. Circulações transnacionais entre Rio de Janeiro e Buenos Aires, 1890-1930 (Río de Janeiro: Arquivo Nacional, 2016). 
estuvieron dirigidos al mejoramiento de las policías que suplían funciones de seguridad.

En este marco, la adopción de un esquema militar comenzó a ser apreciado como la mejor forma de disciplinar y reestructurar el cuerpo. Es por esto que las transformaciones que habían comenzado a realizarse dentro de las fuerzas armadas con la aprobación de la Ley del Servicio Militar Obligatorio de 1901 fueron de especial utilidad. La experiencia de las armas había ganado un peso social significativo, al tiempo que el proceso de imposición del servicio militar había erosionado las lógicas de autonomía y de reciprocidad que caracterizaron a la movilización miliciana durante gran parte del siglo XIX. ${ }^{41}$

Tales aspectos fueron considerados de interés por quienes estaban a cargo de la conducción policial. En efecto, vigorizaron la idea de recuperar un esquema de formación fundamentado en la disciplina y la obediencia. Ello matiza el cuadro brindado por Bayley respecto de la especificidad de las funciones policiales, ya que aquí la apropiación del rol y el carácter militar no parece haber redundado en lo que este autor denomina "especialización imperfecta", sino que fue parte central de su modernización. ${ }^{42}$

Como expresaron algunos comisarios, la educación militarizada supliría las deficientes e infructuosas prácticas de instrucción ensayadas desde el periodo organizativo con la incorporación de los soldados retirados de otras guarniciones como el ejército y las guardias nacionales. Se pensaba que estos defectos podían corregirse mediante el desarrollo de un programa de extensa duración que garantizaría la obediencia a la superioridad y la buena educación de la tropa, al mismo tiempo que propendería a la exaltación de las buenas costumbres, el compañerismo y la caballerosidad. Asimismo, la férrea disciplina era indispensable para asegurar la prescindencia policial de las contiendas políticas, lo que afianzaría su carácter jerárquico y centralizado.

Desde 1902, con el impulso del jefe Luis Doyhenard, los proyectos para adoptar el régimen militar se concretarían. En su concepción, esta vía era la más acorde para conciliar las demandas de la administración política y de las élites intelectuales frente al peligro que suscitaban el perfeccionamiento del delito y la creciente "ola roja". ${ }^{43}$ Además, la policía se promocionaría como uno de los principales mecanismos de modernización social. Los cimientos quedaron establecidos en el proyecto

41. Juan Pablo Fasano y Nicolás Sillitti, “La espada y la balanza. Reflexiones a partir del juzgamiento de la 'revolución' de 1905”, PolHis. Boletín Bibliográfico Electrónico del Programa Buenos Aires de Historia Política 6.11 (2013): 87.

42. Bayley 65-66.

43. Con esa expresión un destacado intelectual, Miguel Cané, cristalizaba hacia 1896 el sentido de amenaza con la que observaba el crecimiento del movimiento obrero en la sociedad francesa. Temeroso de los procesos de expansión política que se orientaban con algunas leyes reformistas a comienzos del siglo XX, instaba a la policía a asumir una posición más férrea para evitar la proliferación de actividades y discursos que consideraba disgregadores del orden social. Remitimos al artículo de Miguel Cané, "La ola roja", Notas e impresiones. Con una introducción de Ernesto Quesada (Buenos Aires: La Cultura Argentina, 1918) 189-194. 
para instruir al personal de las comisarías de campaña en las prácticas castrenses. A tal fin se estipuló que los oficiales seleccionasen "uno á uno" a los agentes para ser remitidos al cuerpo de bomberos de la ciudad de La Plata — capital de la provincia y sede de la Jefatura-, donde recibirían entrenamiento durante 40 días. Esta instancia, integrada al conjunto de experiencias pedagógicas al que hemos referido más arriba, perseguía la transformación del "antiguo vigilante-paisanote de nuestra campaña en un gendarme marcial con educación y espíritu militar, que lo hace doblemente apto para el servicio á que se le destina ordinariamente". ${ }^{44}$

Aunque el esquema militar proyectado para el personal de seguridad solo pervivió en las instancias de instrucción, se cristalizaría en cambio con mayor éxito mediante la creación de cuerpos especializados como el Escuadrón de Seguridad y la Gendarmería Volante. Para la organización de ambas reparticiones, compuestas por unidades de infantería y caballería - ya que las rondas a caballo parecían las más apropiadas para ejercer soberanía en caminos y en territorios extensos-, se combinó un diseño de operación y territorialidad desarrollado al promediar el decenio de 1870 para la custodia de las zonas rurales, ${ }^{45}$ con sistemas policiales europeos de acentuada impronta militar. Esta transposición se enmarca en las articulaciones que Doyhenard logró configurar sobre las tramas de circulaciones de sistemas policiales dinamizado a escala global hacia fines del siglo XIX. ${ }^{46}$

Sin embargo, el interés en adscribir a los proyectos de raigambre castrense no tuvo a Italia, España y Francia como los únicos centros de referencia. Por el contrario, el informe encomendado por Doyhenard al diputado Alberto Cortina, en cuanto antecedente del congreso policial que se realizaría en Río de Janeiro en $1906,{ }^{47}$ puso en cuestión la eficacia de esos modelos y desplazó el ángulo hacia otros espacios nacionales. A partir de un minucioso estudio de la organización y equipamientos de las distintas policías iberoamericanas, Cortina relativizaba la preeminencia europea dado que: "Nos hemos apartado también de la costumbre general, de estudiar en fuentes [...] agenas á las nuestras, en el sueño irrealizable de hacer policías que no son para nosotros y que nuestros pueblos las rechazan enteramente. [...] no se espere nunca, fundadamente, que pueda erijirse una policía parisién ó londinense para que el pueblo se adapte, á la fuerza, á un cúmulo de exigencias inadecuadas". ${ }^{48}$

44. "Título 1. Relación sucinta de las principales resoluciones dictadas por el Jefe de Policía, Señor Luis M. Doyhenard; de las innovaciones y mejoras introducidas en la repartición; y de los nuevos servicios implantados en la misma, desde 1902 hasta 1905”, Boletín de Policía de la Provincia de Buenos Aires (La Plata) 31 de diciembre de 1905: 4.

45. Berardi, "Territorialidad, profesionalización y política" 25-34.

46. Catherine Denys, ed., Circulations policières, 1750-1914 (Villeneuve-d'Ascq: Presses Universitaires du Septentrion, 2012) 9-22.

47. Para una descripción pormenorizada sobre esta y otras experiencias de articulaciones globales e iberoamericanas de la policía local, remitimos a Galeano, Criminosos viajantes 119-147.

48. Alberto Cortina, La policía en Sud-América. Primer estudio general realizado por iniciativa del señor Luis M. Doyhenard. Datos coleccionados por Juan Vucetich, Jefe de la Oficina de Identificación Dactiloscópica (La 
No obstante, a pesar de las proyecciones de construir un sistema policial común a partir de las necesidades sudamericanas, mediante la articulación de las policías de Buenos Aires, Brasil y Uruguay, las experiencias japonesas, ${ }^{49}$ rusa, pero sobre todo la estadounidense, ${ }^{50}$ fueron contempladas como otras referencias posibles, fundamentalmente por sus rasgos militaristas. El interés en estos modelos estaba lejos de una adscripción completa, ya que "ningún sistema es bueno, cuando no encarna la tradición de un pueblo, sus costumbres y sus ideas". Cortina subrayó así el peso del desarrollo militar en la transformación de Estados Unidos como centro de primacía global en el cambio de siglo. Lo que le resultaba modélico de la dirección que debía proseguir la policía bonaerense.

La transposición de elementos de estas experiencias se inscribe entonces dentro del proyecto modernizador impulsado por las jerarquías policiales. Con su aplicación se pretendía, por un lado, concretar la inserción de la policía local en el concierto global; y, por otro lado, se buscaba dinamizar una serie de transformaciones que mejorarían la calidad y la especialización del servicio. En cierta medida, esta experiencia desarrollada en los albores del siglo se sostenía en los aunados esfuerzos de sucesivas jefaturas por concretar una vieja aspiración que buscaba moldear al criollo vigilante o pesquisa en un deseado agente moderno y cosmopolita.

\section{Consideraciones finales}

A la par del ensayo de alternativas de diseño institucional y de articulación territorial, la definición de los mecanismos de inserción, permanencia y movilidad, como de adquisición de una expertisse acorde a las demandas de un escenario cambiante, las cúpulas a cargo de la policía de la provincia de Buenos Aires aplicaron una multiplicidad de estrategias en pos de modernizar y profesionalizar a sus agentes, lo que hacía necesario realizar una mirada en conjunto. De esta manera, pusimos de relieve las formas en que la policía provincial en su tránsito hacia el siglo XX fue construyendo a sus agentes a partir de diversos criterios, y sobre un amplio abanico de requisitos, estrategias y prácticas. Además de heterogéneos, estos fueron cuestionados o simplemente redefinidos al calor de diversas ideas como de la propia experiencia institucional.

Si por momentos el modelo centralizado o la adopción del adoctrinamiento militar integraron un zócalo de ideas que confluirían en mejorar el reconocimiento social policial y el perfeccionamiento de su desempeño, esto no fue en desmedro de la integración de los saberes construidos a partir de la propia experiencia del

Plata:Talleres Gráficos La Popular, 1905) 45.

49. Con notorias influencias del sistema francés, durante la era Meiji el proceso de modernización policial de Japón se caracterizó por adoptar tempranamente un plan de entrenamiento militar autónomo y el establecimiento de escuelas de formación para la tropa. Meron Medzini, French Policy in Japan During the Closing Years of the Tokugawa Regime (Cambridge: East Asian Research Center, Harvard University Press, 1971).

50. Cortina 27. 
patrullaje y la antigüedad en el ejercicio del cargo. Las prácticas de reclutamiento no se tensionaron al encontrarse con una población étnica y culturalmente criolla, forjada en la rutina miliciana al mismo tiempo que conocedora del territorio y adyacente de los sujetos y prácticas objetos de su control.

Observamos así el perfil de los hombres que integraron la policía y, en complemento, revelamos los principales mecanismos y motivaciones de su inserción y reclutamiento. Entre ellos, identificamos al salario en el marco de un tejido relacional y de variantes presupuestarias que incidieron en la profesionalización.

Por otra parte, consideramos en nuestro análisis a las principales instancias de instrucción y diferentes textos que con una lógica programática y rutinaria o con un tono pedagógico modelaron el quehacer policial. Su implementación estuvo, asimismo, signada por un permanente reajuste que las cúpulas realizaron a algunos textos normativos con el objetivo de alcanzar la esfera de atribuciones y el perfil deseado para el escalafón policial, como los manuales de procedimiento y los reglamentos generales de policía.

Este marco programático se articularía fundamentalmente con la trasposición de esquemas transoceánicos de organización policial en un contexto de acentuada y dinámica conexión global. El impulso modernizador alcanzado por el cuerpo policial a partir de 1902, sobre todo debido al proyecto encabezado por Luis María Doyhenard, hizo posible el establecimiento de cuerpos especializados como el Escuadrón de Seguridad y la GendarmeríaVolante, sobre la base de un esquema de instrucción militar que con escasas excepciones trazaría a los esquemas de organización e instrucción que se prolongaron durante gran parte del siglo XX.

\section{Fuentes}

\section{Manuscritas}

Archivo General de la Nación, Buenos Aires (AGN)

Fondo Dardo Rocha, Sala 7

\section{Impresas}

Cané, Miguel. Notas e impresiones. Con una introducción de Ernesto Quesada. Buenos Aires: La Cultura Argentina, 1918.

Cortina, Alberto. La policía en Sud-América. Primer estudio general realizado por iniciativa del señor Luis M. Doyhenard. Datos coleccionados por Juan Vucetich, Jefe de la Oficina de Identificación Dactiloscópica. La Plata:Talleres Gráficos La Popular, 1905.

D’Amico, Carlos. Siete años en el gobierno de la provincia de Buenos Aires. Buenos Aires: Impreta, Litografia y Encuadernación de Jacobo Peuser, 1895.

Ministerio de Gobierno. Memoria presentada á la Honorable Legislatura de la Provincia de Buenos Aires por el Ministro de Gobierno Ing. Francisco Seguí 1887-1888. La Plata: Imprenta Buenos Aires, 1888. 
Policía. Manual de procedimientos. Buenos Aires: Imprenta y Litografía de Buenos Aires, 1881.

Policía de la Provincia. Programa para la instrucción de sargentos, cabos y vigilantes. Arreglado al Reglamento de Policía en vigencia. La Plata:Talleres de Policía, 1904.

Policía de la Provincia de Buenos Aires. Memoria correspondiente al año 1912. Mejoras en el servicio, jefatura del Sr. Juan Carlos Chaumeil. La Plata: Talleres de Policía, 1913.

Provincia de Buenos Aires. Memoria del Departamento de Policía, presentada por Juan A. Domínguez, 1887-1888. La Plata: Imprenta Buenos Aires, 1889.

Registro Oficial de la Provincia de Buenos Aires. Buenos Aires: Imprenta de la Penitenciaría, 1880.

Reglamento General de Policía de la Provincia de Buenos Aires. La Plata: Tipografía Buenos Aires, 1889.

\section{Revistas}

Boletín de Policía de la Provincia de Buenos Aires (La Plata) 1905.

\section{Internet}

http://www.gob.gba.gov.ar

\section{Bibliografía}

Barry,Viviana. "Policía y reclutamiento. Hombres y organización policial en Buenos Aires, 1880-1910”. Ponencia, XII Jornadas Interescuelas / Departamentos de Historia en San Carlos de Bariloche, 2009.

Bayley, David H. Modelos de actividad policial. Un análisis comparativo internacional. Buenos Aires: Prometeo Libros, 2010.

Barreneche, Osvaldo. De brava a dura. Policía de la Provincia de Buenos Aires. Una historia (1930-1973). Rosario: Prohistoria Ediciones, 2019.

. "Manejo metodológico de las fuentes documentales y los archivos de la policía de la provincia de Buenos Aires”. Ponencia, XXVIII Congreso Internacional de LASA, 2019.

Berardi, Pedro. "'Crear la Policía' y construir el territorio. Las reformas policiales en un nuevo orden provincial: Buenos Aires, 1878-1880”. Revista de Historia del Derecho 58 (2019): 1-30.

. "Hacerse visible, mostrarse discreto. El Fondo Luis Doyhenard como cartografia de las confluencias entre la política y la profesionalización policial (1898-1916)". Revista Electrónica de Fuentes y Archivos 6 (2015): 140-159. . "Territorialidad, profesionalización y política. La construcción de la policía en la provincia de Buenos Aires, 1880-1916”. Tesis de doctorado en Historia, Universidad de San Andrés, 2018. 
Bretas, Marcos Luiz. A guerra das ruas. Povo e polícia na cidade do Rio de Janeiro. Río de Janeiro: Arquivo Nacional, 1997.

. "La policía de la capital del Imperio Brasilero". Mirada (de) uniforme. Historia y crítica de la razón policial. Coords. Diego Galeano y Gregorio Kaminsky. Buenos Aires: Editorial Teseo, 2011.

Cárdenas Muñoz, Vania. El orden gañán. Historia social de la policía. Valparaíso, 18961920. Chile: Ediciones Escaparate, 2013.

Carrizo, Gabriel. “Pobres peligrosos e incapaces'. La policía del Territorio Nacional del Chubut entre fines del siglo XIX y primeras décadas del siglo XX". Historia social y política del delito en la Patagonia. Comp. Gabriel Rafart. Neuquén: Editorial de la Universidad Nacional del Comahue, 2010.

Denys, Catherine. Ed. Circulations policières, 1750-1914. Villeneuve-d'Ascq: Presses Universitaires du Septentrion, 2012.

Emsley, Clive. "Los modelos de policía en el siglo XIX". Mirada (de) uniforme. Historia y crítica de la razón policial. Coords. Diego Galeano y Gregorio Kaminsky. Buenos Aires: Editorial Teseo, 2011.

."The Policeman as Worker: A Comparative Survey c. 1800-1940”. International Review of Social History 45.1 (2000): 89-110.

Fasano, Juan Pablo y Nicolás Sillitti. "La espada y la balanza. Reflexiones a partir del juzgamiento de la 'revolución' de 1905”. PolHis. Boletín Bibliográfico Electrónico del Programa Buenos Aires de Historia Política 6.11 (2013): 82-93.

Fernández Marrón, Melisa. "El agente policial / modelo para armar. Estrategias institucionales de profesionalización en el territorio nacional de $\mathrm{La}$ Pampa (1930-1950)". Ponencia, I Jornadas Nacionales de Historia Social, 2007.

Galeano, Diego. Criminosos viajantes. Circulações transnacionais entre Rio de Janeiro e Buenos Aires, 1890-1930. Río de Janeiro: Arquivo Nacional, 2016.

. "O oficio inconfessável: policiais, ordem urbana e mercado de trabalho na cidade de Buenos Aires, 1867-1880". Revista do Arquivo Geral da Cidade do Rio de Janeiro 9 (2015): 191-209.

García Ferrari, Mercedes. Marcas de identidad. Juan Vucetich y el surgimiento transnacional de la dactiloscopia (1888-1913). Rosario: Prohistoria Ediciones, 2015.

Gayol, Sandra. "Entre lo deseable y lo posible. Perfil de la policía de Buenos Aires en la segunda mitad del siglo XIX”. Estudios Sociales 10 (1996): 123-138. DOI: 10.14409/es.v10i1.2355.

."Sargentos, cabos y vigilantes: perfil de un plantel inestable en el Buenos Aires de la segunda mitad del siglo XIX”. Boletín Americanista 46 (1996): 133-151.

Losada, Leandro. "La sociedad bonaerense: tendencias demográficas, grupos sociales y formas de vida". Historia de la Provincia de Buenos Aires. De la federalización de Buenos Aires al advenimiento del peronismo (1880-1943). Tomo 4. Dir. Juan Manuel Palacio. Buenos Aires: UNIPE Editorial Universitaria 
/ Edhasa, 2013.

Medzini, Meron. French Policy in Japan During the Closing Years of the Tokugawa Regime. Cambridge: East Asian Research Center, Harvard University Press, 1971.

Pérez, Pilar. "De la ocupación militar del Desierto a la práctica policial como productoras del espacio social en Nor-Patagonia (Río Negro, 1884-1914)”. Ponencia, Jornada de Debate: “Administración territorial, milicia y policía en perspectiva comparada: Buenos y Río Negro entre 1852 y 1916”, 2017.

Pulido Esteva, Diego. “Trabajo, clase y prácticas policiales en las comisarías de la ciudad de México, 1870-1920”. Historia Mexicana 68.2 (2018): 667-712. DOI: $10.24201 / \mathrm{hm} . v 68 \mathrm{i} 2.3749$.

Rocchi, Fernando. "La economía bonaerense: del auge exportador a su crisis". Historia de la Provincia de Buenos Aires. De la federalización de Buenos Aires al advenimiento del peronismo (1880-1943). Tomo 4. Dir. Juan Manuel Palacio. Buenos Aires: UNIPE Editorial Universitaria / Edhasa, 2013.

Sedeillan, Gisela. La justicia penal en la provincia de Buenos Aires. Instituciones, prácticas y codificación del derecho (1877-1906). Buenos Aires: Editorial Biblos, 2012.

Sedeillan, Gisela y Pedro Berardi. "El desafio de la policía bonaerense en la década de 1890: entre la expansión institucional y el estancamiento de sus recursos". Prohistoria 18.23 (2015): 71-96. 